\title{
The Federal Institute for Geosciences and Natural Resources - Germany's Geoscientific Centre
}

The Federal Institute for Geosciences and Natural Resources (Bundesanstalt für Geowissenschaften und Rohstoffe) - BGR is Germany's geoscientific centre of competence within the Federal Government and part of its scientific and technical infrastructure. BGR is accountable to the Federal Ministry of Economics and Technology, providing independent advice and information on all geoscientific and natural resources issues. In particular, BGR supports the Federal Government in their following objectives:

- Stimulating economic development

- Long-term protection and improvement of the quality of life

- Enhancing technical and scientific expertise.

Currently, about 740 scientists, engineers, technicians and administrative employees and civil servants form BGR's staff, 510 of which are permanent and 230 are on temporary contracts.

\section{History of BGR}

In 1873, the Geological Survey of Prussia (Königlich Preußische Geologische Landesanstalt) was established in Berlin. Germany's independent state geological surveys were integrated into the Reichsstelle

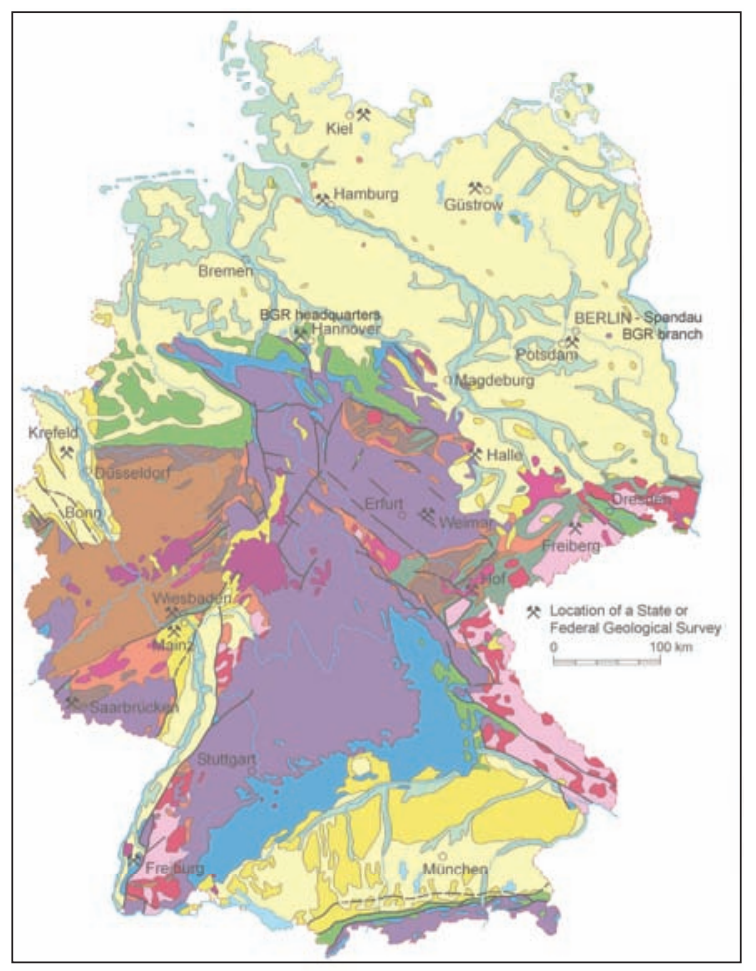

Geological map of Germany (http://www.infogeo.de/home) für Bodenforschung, Berlin in 1939 and was renamed Reichsamt für Bodenforschung in 1941. The State survey organizations became branch offices. In 1945, the branch office at Hannover was reorganized. In the territory of the former German Democratic Republic (GDR), the national Geological Commission - later named Zentrales Geologisches Institut - was established, with its headquarters in Berlin. The regional Geological Survey for Lower Saxony (The Amt für Bodenforschung) was established in Hannover in 1950. On administrative agreement between the Federal Republic of Germany and the State of Lower Saxony, the Bundesanstalt für Bodenforschung in Hannover was founded by Decree of the Federal Minister of Economics on 26.11.1958. In 1971, Gräfenberg Central Seismological Observatory was integrated in the Bundesanstalt and in 1975 Bundesanstalt für Bodenforschung was renamed Bundesanstalt für Geowissenschaften und Rohstoffe - BGR (Federal Institute for Geosciences and Natural Resources). BGR's branch office was opened in 1990 in Berlin, incorporating the former Zentrale Geologische Institut of GDR. The Berlin branch was integrated in 1997 with the BGR-departments and renamed Berlin Regional Office. The German Mineral Resources Agency (The Deutsche Rohstoffagentur, DERA) after being inaugurated in October 2010, takes its seat in the BGR's Berlin Regional Office in March 2012.

\section{Major Programs and} Significant Results

BGR is active in the following fields of scientific research

\section{Energy Resources}

BGR applies and develops exploration methods and strategies in the run-up of industrial activities, in particular in marine frontier zones and on unconventional energy resources. Our marine geophysical survey facilities include modern multi-channel reflection seismics, which will be extended to $3 \mathrm{D}$ and CSEM (Controlled-SourceElectromagnetic Method). BGR is monitoring and evaluating the global availability of nonrenewable fuels. As consultant to the Federal Government and German industry, BGR continuously analyses and evaluates global developments in reserves, resources, exploration and markets for crude oil, natural gas, coal and uranium. Based on this expertise, the recently established German Mineral Resources Agency (DERA), serves as an advisory body for the German industry. BGR also compiles information on nonconventional oil and gas fields in Germany, and analyses their economic potential.

\section{Mineral Resources}

BGR continuously analyses and evaluates global mineral resource potentials and markets for metals, non-metals, and industrial minerals. It also develops new exploration methods and strategies in the run-up to industrial activities. In the interest of safeguarding the continuous supply of natural resources, BGR provides its know-how in the field of natural resources and mining including the exploration of deposits of natural resources from prospecting to production and finally to closure, abandonment and land reclamation. One of the priorities of the newly established DERA is 
to increase market transparency. Special emphasis is also given on the use of mine tailings as secondary sources of raw materials and verification of the origin of "conflict minerals". In addition to exploration work on marine manganese nodules, exploration of polymetallic sulphide deposits at mid-oceanic ridges will be a research target in coming years.

\section{Groundwater}

BGR develops scientific methods for improving groundwater management. Together with other institutions from Germany, Europe and overseas, BGR works on improved regional groundwater information systems. BGR supports national and international legislative and development policy measures for securing groundwater resources and contribute to integrated water resource management. Due to boosting food production and related irrigation of farmland, groundwater pumping will increase around the world in coming decades. BGR develops methods and manages projects for the controlled recharge of groundwater resources by deliberate infiltration of rain water that would otherwise run-off unused.

\section{Soil}

BGR collects and evaluates data on soils necessary for decision support instruments on soil use, soil protection and sustainable land management. Soil is a valuable, yet finite resource, subject to degradation due to natural and anthropogenic processes. Soil protection demands for further improvements in our understanding of the distribution and properties of soils. Through applied research BGR develops tools and standards for soilrelated information. BGR cooperates with the pedological services of Germany's Federal States and European nations.

\section{Safe Disposal of Radioactive Waste}

BGR contributes to efforts aimed at the permanent disposal of radioactive waste. The German Federal Office for Radiation Protection (BfS) uses BGR's know-how for solving geoscientific and geotechnical problems when erecting installations for the final disposal of such waste. BGR also performs its own basic research on geological site exploration and evaluation, characterization of rock mechanics of the potentially suitable host rocks, analysis of the stability of final repository structures and on long-term stability scenarios. BGR's activities in this field are often carried out through extensive cooperation with international partners and in association with other research institutions.

\section{Deep Subsurface Use; Geological $\mathrm{CO}_{2}$ Storage}

In accordance with an agreement between the Federal Ministry of Economics and Technology and the Federal Ministry for Economic Cooperation and Development, BGR is one of Germany's implementation organizations for technical cooperation with developing nations. Projects are carried out in the fields of mining, resources, groundwater, soil, georisks, geology, and environmental protection. BGR thereby supports the Federal Government in achieving its foreign trade and stability policy objectives as we are committed to international development goals and strive to sustainably alleviate poverty and structural deficits in accordance with the UN Millennium Declaration. A key element of BGR's international cooperation activities is capacity building together with strengthening good governance, self-responsibility, and selfhelp resources in partner countries.

\section{Geoscientific Information}

BGR participates at both national and international levels in fundamental geological research. In cooperation with Germany's regional geological surveys and the national geological surveys of Europe, we provide thematic geological information, maps, standards and methodologies. Together with many other institutions, BGR contributes to the development of the geodata infrastructure (geoinformation business) and intensively work on the standardization and interoperabilization of geodata covering geology, pedology, hydrogeology and natural resources. BGR also does research work on the continental geology of Antarctica and thus contributes to the fulfillment of the obligations required for preserving the country's consultative status in the Antarctic treaty.

\section{Nuclear Weapons Test Ban; Geo-hazard Assessment}

BGR fulfils Germany's obligations with regard to the international Comprehensive Test Ban Treaty (CTBT), on behalf of the Federal Government. It operates the national CTBT data centre, where seismic signals from suspected nuclear weapons' test explosions are detected and recorded. In addition, BGR monitors global earthquake activities by its national seismological observatory. We also develop methods helping to reduce geological hazards such as volcanic eruptions, landslides, tsunamis or subsidence and advise partner countries and regions in natural catastrophe management.

\section{Vision for future work}

Over the last decades, geosciences have gained a remarkable appreciation by the public. In fact, geological knowledge in a truly broad sense is crucially needed to solve the big challenges of mankind in future: sufficient water, food, energy, commodities for a comfortable life, and adequate protection against natural hazards. All this is required for an estimated population of 9 billion people by the year 2050. Clearly, we have to optimize our supply concepts and increase efficiency. Fortunately, through modern media, experts' knowledge has become more easily available than ever before, facilitating the emergence of intelligent strategies, new technologies and sustainable solutions anywhere on Earth. Geological Surveys will continue to play a prominent role in any nation. Progress will inevitably be based on measures taken in view of the local and regional geologic conditions.

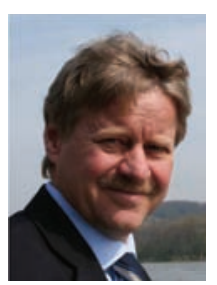

Prof. Hans-Joachim Kümpel grew up in the town of Essen. He studied mathematics at Freiburg University and Geophysics at Kiel University. With a diploma in geophysics (1977) and a PhD in natural sciences (1982), he spent a year at Dalhousie University in Halifax, Canada, specialising on mechanical rockfluid interaction. From 1991 to 2001, he was Professor in Applied Geophysics at Bonn University, and was appointed director of the Leibniz Institute for Applied Geophysics in Hannover from 2001 to 2007. Since August 2007, Prof. Kümpel is president of BGR. 